\title{
Microflorae of aquatic moss pillars in a freshwater lake, East Antarctica, based on fatty acid and 16S rRNA gene analyses
}

\author{
Ryosuke Nakai $\cdot$ Takashi Abe $\cdot$ Tomoya Baba $\cdot$ Satoshi Imura $\cdot$ Hiroshi Kagoshima $\cdot$ Hiroshi Kanda $\cdot$ \\ Atsuko Kanekiyo · Yuji Kohara · Akiko Koi · Keiko Nakamura · Takanori Narita • \\ Hironori Niki $\cdot$ Katsuhiko Yanagihara $\cdot$ Takeshi Naganuma
}

Received: 11 March 2011 / Revised: 11 August 2011 / Accepted: 12 August 2011 / Published online: 30 August 2011

(C) The Author(s) 2011. This article is published with open access at Springerlink.com

\begin{abstract}
Aquatic mosses in the genera Bryum and Leptobryum form unique tower-like "moss pillars" underwater in some Antarctic lakes, in association with algae and cyanobacteria. These are communities with a two-layer structure comprising an oxidative exterior and reductive interior. Although habitats and photosynthetic properties of moss pillars have been reported, microfloral composition of
\end{abstract}

Electronic supplementary material The online version of this article (doi:10.1007/s00300-011-1090-2) contains supplementary material, which is available to authorized users.

R. Nakai $\cdot$ A. Kanekiyo $\cdot$ A. Koi $\cdot$ K. Nakamura .

T. Naganuma ( $\square)$

Graduate School of Biosphere Science, Hiroshima University,

1-4-4 Kagamiyama, Higashi-Hiroshima 739-8528, Japan

e-mail: takn@hiroshima-u.ac.jp

R. Nakai

Research Fellow of the Japan Society for the Promotion of Science, Chiyoda-ku, Tokyo 102-8471, Japan

T. Abe

Nagahama Institute of Bio-Science and Technology,

1266 Tamura-cho, Nagahama, Shiga 526-0829, Japan

T. Baba $\cdot$ H. Kagoshima $\cdot$ K. Yanagihara

Transdisciplinary Research Integration Center,

4-3-13 Toranomon, Minato-ku, Tokyo 105-0001, Japan

$\mathrm{S}$. Imura $\cdot \mathrm{H}$. Kanda

National Institute of Polar Research, 10-3 Midori-cho,

Tachikawa, Tokyo 190-8518, Japan

H. Kagoshima $\cdot$ Y. Kohara $\cdot$ H. Niki

National Institute of Genetics, 1111 Yata, Mishima,

Shizuoka 411-8540, Japan

T. Narita

Department of Veterinary Medicine, Nihon University, 1866 Kameino, Fujisawa, Kanagawa 252-8510, Japan the two-layer structure has not been described. Here we report fatty acid analysis of one moss pillar and molecular phylogenetic analysis, based on the 16S rRNA gene, of this and one other moss pillar. Cluster analysis of the phospholipid fatty acid composition showed three groups corresponding to the exterior, upper interior, and lower interior of the pillar. This suggested that species composition differed by section, with the exterior dominated by photosynthetic organisms such as mosses, algae, and cyanobacteria, the upper interior primarily containing gram-positive bacteria and anaerobic sulfate-reducing bacteria, and the lower interior dominated by gram-negative bacteria. Molecular phylogenetic analysis revealed that Proteobacteria dominate the moss pillar as a whole; cyanobacteria were found on the exterior and the gram-positive obligate anaerobe Clostridium in the interior, while gram-positive sulfatereducing bacteria were present in the lowest part of the interior. Nitrogen-fixing bacteria and denitrifying bacteria were found in all sections. Thus, fatty acid analysis and genetic analysis showed similar patterns. These findings suggest that microorganisms of different phylogenetic groups inhabit different sections of a single moss pillar and form a microbial community that performs biogeochemical cycling to establish and maintain a structure in an oxidation-reduction gradient between exterior and interior.

Keywords Antarctic lake $\cdot$ Moss pillars - Biodiversity · Fatty acid $\cdot 16 \mathrm{~S}$ rRNA gene $\cdot$ Bacteria

\section{Introduction}

As Antarctica is cold, dry, and mostly covered in ice, the terrestrial ecosystem of all but a small part of the continent is oligotrophic. Algae, lichens, and mosses can be found in 


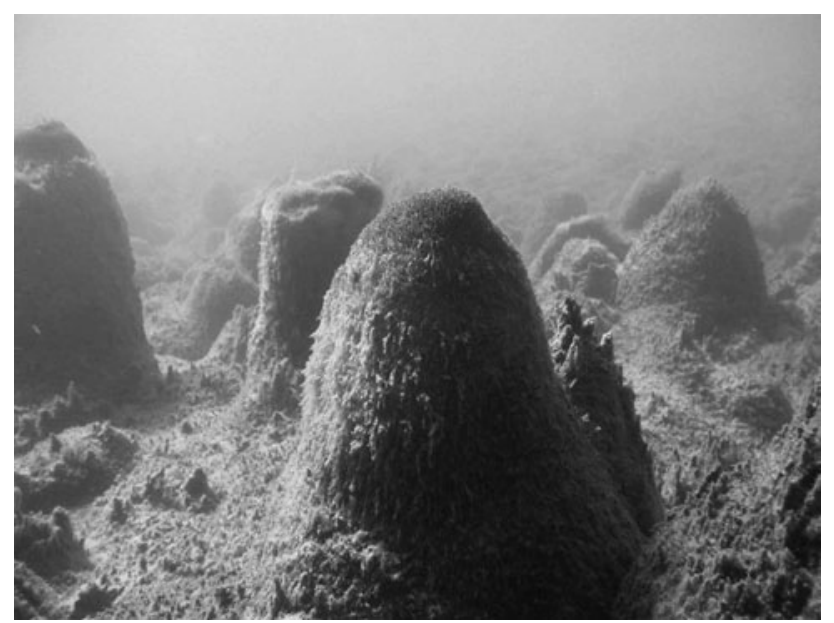

Fig. 1 Antarctic moss pillar found in Hotoke-Ike Lake. Photo Dr. Imura

limited regions such as ice-free areas at the continental margins (Beyer and Bölter 2002). Many lakes of varying water quality, ranging from freshwater to hypersaline, are dotted around the ice-free areas (Imura et al. 2003; Gibson et al. 2006), and these lake ecosystems are thought to be oligotrophic. However, the view that Antarctic lake ecosystems are rather meager was revised following the discovery of benthic "moss pillars" by the 36th Japanese Antarctic Research Expedition. These pillars are formed by large colonies of aquatic mosses in lakes around Syowa Station (Imura et al. 1999; Fig. 1), resulting in an undulating green landscape of luxuriant vegetation. The pillars are unique tower-like structures originating from the algal mats on the lake bottom. The largest specimens are $40 \mathrm{~cm}$ in diameter and $80 \mathrm{~cm}$ high (Imura 2006). The primary component is densely intertwined strands of Leptobryum sp. forming a single pillar-like structure, with a Bryum sp. as a minor component (Ohtani et al. 2001). There are no reported examples of terrestrial Leptobryum sp. around Syowa Station in East Antarctica where the moss pillars were discovered, and it is unclear how these colonized the lakes. Moreover, no moss pillars have been reported from other areas or polar lakes. Imura and Kanda (2002) believed that Leptobryum sp. may have originated outside Antarctica.

Since the first description of the pillars by Imura et al. (1999), research has included moss pillar growth rate using radiocarbon dating (Imura et al. 2000), component moss species and attached algae (Ohtani et al. 2001), distribution of aquatic mosses around Syowa Station (Imura et al. 2003), carbon, nitrogen, and chlorophyll $a$ levels in apical and basal parts of pillars (Kudoh et al. 2003a; Imura 2006), temperature and light environment of the moss habitat (Kudoh et al. 2003b; Tanabe et al. 2008; Kimura et al. 2010), photochemical activity of apices and sides of pillars (Kudoh et al. 2003c, 2009), and characteristics of lake sediments (Iwasa et al. 2000; Matsumoto et al. 2006). Since the discovery of the pillars, the Research on Ecology and Geohistory of Antarctic Lakes (REGAL) Project was organized in Japan and the shape and water quality of many lakes have been investigated. Data were disclosed in Kimura et al. (2010). In addition, the environmental and genetic approach for life on earth, with a study of relevant modeling and prediction techniques, (EAGLE) project was also begun in Japan. The goal of the EAGLE project is to improve our understanding of earth's ecosystems and to investigate the mechanisms leading to the evolution of life and the adaptation of species to past environmental change (Kanda 2009).

Surfaces of moss pillars are green and copious oxygen bubbles resulting from photosynthesis have been observed on the apices. The cyanobacterium Leptolyngbya sp. and the diatom Amphora sp. are attached to the sides of moss pillars (Ohtani et al. 2001; Ohtsuka et al. 2006), while the interior is packed with brown Leptobryum sp. Thus, the pillars have a two-layer structure, a green exterior and a dark brown interior. The exterior is an aerobic environment where photosynthesis is performed by moss and cyanobacteria, whereas the interior is decomposing and gives off a strong odor of rotten eggs; it has been suggested that the exterior and interior may be within oxygen gradients (Kudoh et al. 2003a).

In this way, while knowledge has accumulated on the morphological and limnological features of the Antarctic moss pillars, the community structures of the microorganisms involved in these unique communities have not so far been investigated. In particular, information about the microflora of the pillars is limited to microscopic observations of cyanobacteria and diatoms. Microfloral phylogeny and diversity have not been studied in detail. A pillar can be considered an ecosystem in which mosses and their associated microflora cooperate in production and in nutrient recycling. The microflora may play a key role in the establishment and maintenance of these ecosystems.

We used biochemical and molecular methods to elucidate the microflora of aquatic moss pillars. We performed fatty acid analysis on samples taken from one pillar and molecular phylogenetic analysis of the 16S rRNA gene on samples taken from two pillars. Our findings will enable discussion of the phylogeny, biodiversity, and related biochemical processes, in the moss pillars and in other aquatic vegetation in polar environments.

\section{Materials and methods}

Study area and sampling strategy

Antarctic moss pillar specimens were harvested on January 19, 2000, by the 42nd Japanese Antarctic Research Expedition at Hotoke-Ike Lake $\left(69^{\circ} 28^{\prime} \mathrm{S}, 39^{\circ} 34^{\prime} \mathrm{E}\right)$, Skarvsnes, in 
Fig. 2 Map of the study site. Hotoke-Ike Lake, formerly known as B-4-Ike, is located in the Skarvsnes ice-free area near Syowa Station in East Antarctica. Black areas represent icefree areas

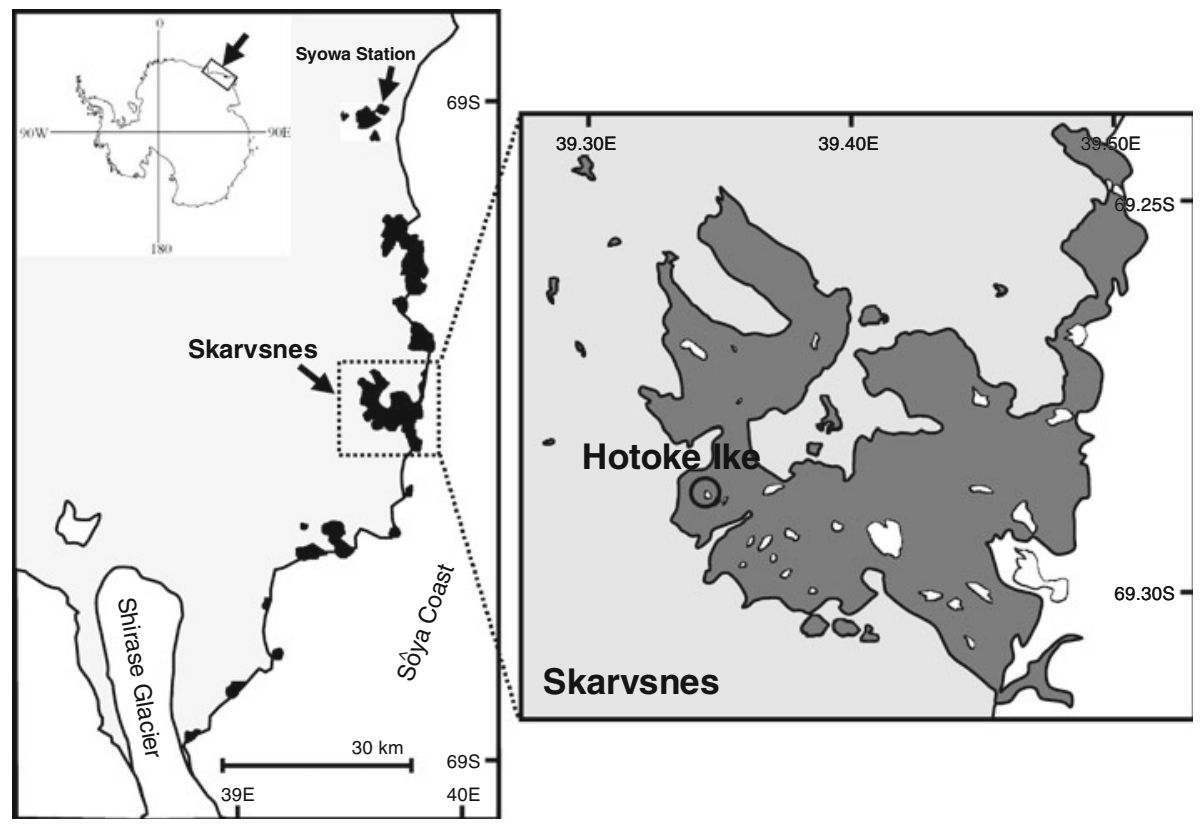

the vicinity of Syowa Station in East Antarctica (Fig. 2). Hotoke-Ike Lake was not frozen when we collected our samples. The lake water had a water conductivity of $107.1 \mathrm{~ms} \mathrm{~m}^{-1}$, a temperature of $3.7^{\circ} \mathrm{C}$, a dissolved oxygen level of $12.0 \mathrm{mg} \mathrm{l}^{-1}$, and a pH of 7.01 (Kudoh et al. 2003b). Wherever possible, we used new, unused equipment such as boats, water sampling equipment, and ropes. Any equipment that had been used in Japan was thoroughly washed before transport to the Antarctic. Two specimens were collected. Specimen A was $22 \mathrm{~cm}$ in diameter and $30 \mathrm{~cm}$ high. Specimen $\mathrm{B}$, used to check the reproducibility of the genetic analysis, was $20 \mathrm{~cm}$ in diameter and $27 \mathrm{~cm}$ high. The specimens were placed in buckets and immediately transferred to the laboratory on board the icebreaker Shirase by helicopter. They were stored at $-20^{\circ} \mathrm{C}$ prior to analysis.

Fatty acid analysis

Each moss pillar specimen was thawed and sectioned into 14 samples (7 exterior, 7 interior) by separating interior from exterior and dividing each longitudinally into seven horizontal sections. Exterior sections were labeled O1-O7, and interior sections were labeled I1-I7 (Fig. 3). Sections were prepared by freeze-drying and then grinding with a sterilized mortar and pestle. Resultant samples were added to $2 \mathrm{ml}$ of phosphate buffer, $3 \mathrm{ml}$ of chloroform, $6 \mathrm{ml}$ of methanol, and left to stand for $24 \mathrm{~h}$. Phospholipids and neutral lipids were eluted in methanol and chloroform, respectively, and fractionated using a Silica Sep-Pak column (100 mg silica, Waters Associates). The eluted phospholipids and neutral lipids were methyl-esterified as previously described (Rajendran et al. 1992), to produce phospholipid fatty acids (PLFA) and neutral lipid fatty acids (NLFA).

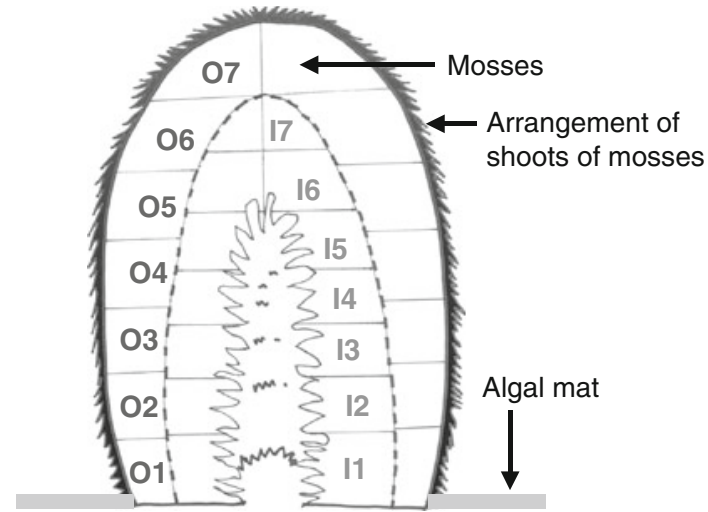

Fig. 3 Fourteen sections apportioned from each moss pillar specimen. Exterior and interior sections are labeled O for "outer" and I for "inner," with numbering from bottom to top of the pillar. In the tall pillar, middle basal parts of them were decomposed and became a cavity

Extracts were analyzed by Agilent 6890 GC (Agilent Technologies, Little Falls, DE, USA) following Kanekiyo et al. (2005). Inter-sample similarities based on fatty acid composition ratios were calculated as Euclidean distances, and cluster analysis was performed using SPSS (SPSS Inc., Chicago, IL, USA).

Genomic DNA extraction, PCR amplification, and clone library generation

Each of the 14 sections apportioned for fatty acid analysis was also used to provide samples for genomic DNA extraction. Mixed microbial genomic DNA was extracted by applying a partially modified version of the bead-beating method reported by Miller et al. (1999) to $500 \mathrm{mg}$ (dry weight) of each sample. A subsample (100 mg dry weight) 
was placed in a 2-ml screw-cap microtube, with $1.2 \mathrm{~g}$ of sterilized $0.1 \mathrm{~mm}$ diameter zirconium/silica beads (BioSpec Products Inc., Bartlesville, OK, USA), $0.3 \mathrm{ml}$ of phosphate buffer (100 mM NaH $\left.\mathrm{PO}_{4}, \mathrm{pH} 8.0\right), 0.3 \mathrm{ml}$ of lysis buffer (10\% SDS, $100 \mathrm{mM} \mathrm{NaCl}, 500 \mathrm{mM}$ Tris- $\mathrm{HCl}, \mathrm{pH} 8.0$ ), and $0.3 \mathrm{ml}$ of chloroform/isoamyl alcohol (24:1). The microtube was set in a Mini Bead-Beater 8 (BioSpec Products) and centrifuged (3,200 rpm, $3 \mathrm{~min}$ ). Beads and broken cell fragments in the tube were then removed by centrifugation $(15,000 \mathrm{rpm}, 5 \mathrm{~min})$. The supernatant was purified using a Mag Extractor-Genome kit (Toyobo, Osaka, Japan) following the manufacturer's instructions. A PCR clone library was generated from the 16S rRNA gene in the purified genomic DNA. Bacteria-specific 27F, Archaea-specific 21F, and universal $1492 \mathrm{R}$ were used as PCR primers to amplify the $16 \mathrm{~S}$ rRNA gene along most of its length (DeLong 1992). PCR reaction conditions followed Naganuma et al. (2007). The PCR-amplified products were cloned using TOPO TA cloning kit (Invitrogen, Carlsbad, CA, USA) before transformation in Escherichia coli TOP10 (Invitrogen). The nucleotide sequences of inserted 16S rRNA genes were determined using an ABI 3730XL automatic DNA sequencer (Applied Biosystems, Foster City, CA, USA).

Phylogenetic analysis based on the 16S rRNA gene

Similar sequences were clustered into phylotypes using the CD-hit program (Li and Godzik 2006) with a minimum coverage of $97 \%$ and a minimum identity of $97 \%$. For phylotypes of two or more clones, 16S rRNA gene sequence mutations were compared and representative clones were defined as those with the highest proportions of mutations over all nucleotides. These phylotypes were checked for chimeras using RDPII chimera detection (Maidak et al. 2001) and Web-Pintail (Ashelford et al. 2005). Classified phylotypes were compared with known 16S rRNA gene sequences by BLASTN search (Altschul et al. 1997) against the NCBI nt-database. Each phylotype was classified using the RDP II Naive Bayesian rRNA Classifier, Version 2.0 (Wang et al. 2007), and rarefaction analysis of microbial diversity was completed with the Rarefaction Calculator (http://www.biology.ualberta.ca/jbrzusto/rarefact.php). The 16S rRNA gene sequences of the phylotypes obtained from our PCR clone library analysis have been deposited in the DDBJ/EMBL/GenBank database under the accession numbers AB630383 to AB630946.

\section{Results and discussion}

Moss pillar microflora deduced from fatty acid composition

Cluster analysis of the fatty acid composition of the 14 samples from moss pillar A found phospholipid fatty

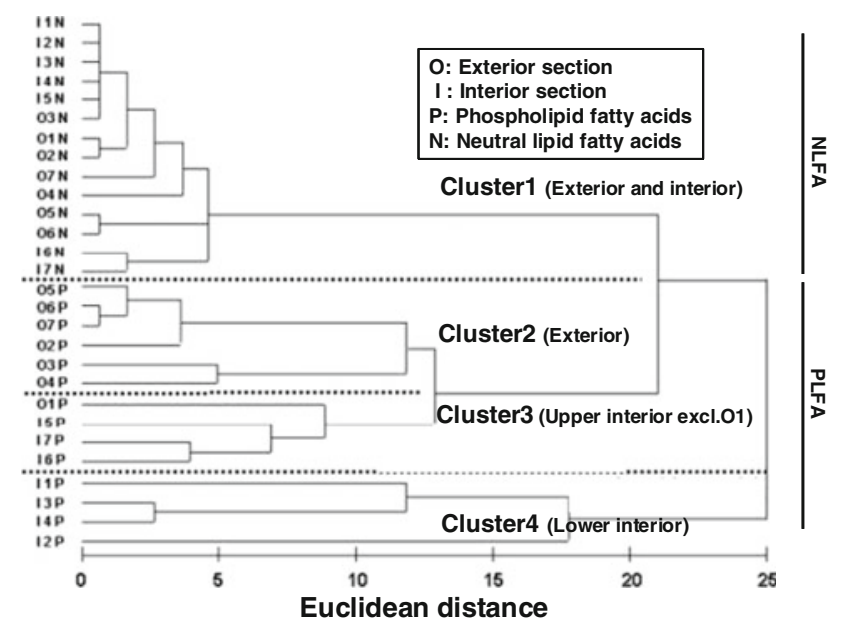

Fig. 4 Dendrogram based on fatty acid composition in a sectioned moss pillar. Data are labeled in the same manner as in Fig. 3 with the addition of $\mathrm{P}$ and $\mathrm{N}$ designating phospholipid fatty acids and neutral lipid fatty acids, respectively

acids (PLFAs, mainly from living organisms) divided into three groups: cluster 2 (exterior), cluster 3 (upper interior), and cluster 4 (lower interior) (Fig. 4; Table S1). The lowest exterior section (O1) also appeared in cluster 3. In cluster 2, characteristic fatty acids were markers of photosynthetic organisms such as mosses, algae, and cyanobacteria $(18: 2 \omega 6,18: 3 \omega 3)$; in cluster 3 , fatty acids were markers of gram-positive bacteria and the anaerobic sulfate-reducing bacterium Desulfovibrio (i15:0, a15:0, i16:0); and in cluster 4 , fatty acids were markers of gram-negative bacteria $(18: 1 \omega 9 \mathrm{c}, 18: 1 \omega 7 \mathrm{c}, 19: 0 \mathrm{cyc})$ (Findlay et al. 1990). In cluster 4, the lowest section (I1-I2) was dominated (66.3-75.3\%) by fatty acid 19:0cyc, indicating that bacteria were the mainstay of this site. Neutral lipid fatty acids (NFLAs) are mainly from stored lipids and decomposition products of PLFA (Christie 1982) and lack the diversity of PLFA (cluster 1), with $18: 2 \omega 6$ and $18: 3 \omega 3$ accounting for $40.1-52.5 \%$ of diversity in every site. Since these fatty acids are unique to eukaryotes (Findlay et al. 1990), we have inferred that the NLFAs originated from fatty acids accumulated by mosses. These results suggest that the moss pillar exterior is dominated by photosynthetic autotrophs, whereas the interior and lowest exterior are dominated by bacteria and have few photosynthetic autotrophs. In addition, gram-positive and anaerobic sulfate-reducing bacteria dominate the upper interior and gram-negative bacteria dominate the lower interior. The lowest exterior section (O1), which grouped with the upper interior sections in cluster 3 , may have been contaminated by sediment that was directly beneath the moss pillars when specimens were harvested. 
Table 1 Distribution of phylotypes and clones in the specimen A moss pillar sections

\begin{tabular}{|c|c|c|c|c|c|c|c|c|c|c|c|c|c|c|c|c|}
\hline \multirow[t]{3}{*}{ Phylogenetic group } & \multirow{3}{*}{$\begin{array}{l}\text { No. of } \\
\text { phylotype }\end{array}$} & \multirow{3}{*}{$\begin{array}{l}\text { No. of } \\
\text { clones }\end{array}$} & \multicolumn{14}{|c|}{ Distribution of clones } \\
\hline & & & \multicolumn{7}{|c|}{ Exterior section } & \multicolumn{7}{|c|}{ Interior section } \\
\hline & & & $\mathrm{O} 1$ & $\mathrm{O} 2$ & $\mathrm{O} 3$ & $\mathrm{O} 4$ & $\mathrm{O} 5$ & O6 & $\mathrm{O} 7$ & I1 & $\mathrm{I} 2$ & $\mathrm{I} 3$ & $\mathrm{I} 4$ & I5 & I6 & $\mathrm{I} 7$ \\
\hline Cyanobacteria & 9 & 65 & 14 & 19 & 4 & 1 & 8 & 8 & 11 & 0 & 0 & 0 & 0 & 0 & 0 & 0 \\
\hline Alphaproteobacteria & 59 & 347 & 19 & 23 & 26 & 27 & 34 & 27 & 28 & 20 & 23 & 25 & 18 & 29 & 21 & 27 \\
\hline Betaproteobacteria & 16 & 74 & 4 & 6 & 6 & 4 & 6 & 3 & 2 & 10 & 8 & 7 & 5 & 3 & 4 & 6 \\
\hline Gammaproteobacteria & 5 & 12 & 0 & 0 & 3 & 0 & 0 & 1 & 1 & 0 & 5 & 0 & 1 & 0 & 0 & 1 \\
\hline Deltaproteobacteria & 30 & 112 & 4 & 2 & 11 & 19 & 9 & 10 & 7 & 6 & 5 & 7 & 9 & 4 & 10 & 9 \\
\hline Unclassified proteobacteria & 1 & 6 & 0 & 1 & 1 & 0 & 1 & 1 & 0 & 0 & 1 & 1 & 0 & 0 & 0 & 0 \\
\hline Bacteroidetes & 23 & 62 & 2 & 3 & 2 & 3 & 2 & 1 & 4 & 3 & 2 & 10 & 9 & 9 & 5 & 7 \\
\hline Nitrospirae & 2 & 12 & 0 & 0 & 1 & 0 & 0 & 0 & 0 & 2 & 3 & 2 & 1 & 1 & 1 & 1 \\
\hline Firmicutes & 12 & 47 & 0 & 0 & 0 & 0 & 0 & 0 & 0 & 13 & 5 & 5 & 4 & 7 & 8 & 5 \\
\hline Chloroflexi & 41 & 98 & 5 & 15 & 4 & 7 & 6 & 7 & 7 & 9 & 9 & 5 & 8 & 5 & 6 & 5 \\
\hline Actinobacteria & 12 & 25 & 0 & 0 & 1 & 1 & 2 & 0 & 1 & 1 & 2 & 4 & 1 & 4 & 4 & 4 \\
\hline Planctomycetes & 36 & 99 & 4 & 3 & 6 & 5 & 8 & 10 & 10 & 5 & 10 & 8 & 11 & 6 & 5 & 8 \\
\hline Acidobacteria & 19 & 38 & 2 & 2 & 4 & 2 & 1 & 2 & 2 & 0 & 2 & 4 & 4 & 3 & 5 & 5 \\
\hline Verrucomicrobia & 10 & 24 & 3 & 1 & 2 & 3 & 3 & 3 & 2 & 0 & 2 & 1 & 0 & 1 & 1 & 2 \\
\hline Candidate division & 6 & 34 & 17 & 2 & 0 & 0 & 0 & 1 & 1 & 2 & 3 & 2 & 2 & 1 & 2 & 1 \\
\hline OP11 & (1) & $(10)$ & (7) & (1) & $(0)$ & (0) & $(0)$ & $(0)$ & $(0)$ & (1) & (1) & $(0)$ & $(0)$ & $(0)$ & $(0)$ & $(0)$ \\
\hline OD1 & (1) & $(8)$ & (6) & $(0)$ & $(0)$ & (0) & $(0)$ & $(1)$ & $(1)$ & $(0)$ & $(0)$ & $(0)$ & $(0)$ & $(0)$ & $(0)$ & (0) \\
\hline TM7 & (2) & $(10)$ & (4) & (1) & $(0)$ & (0) & $(0)$ & $(0)$ & $(0)$ & (1) & (2) & (2) & $(0)$ & $(0)$ & $(0)$ & (0) \\
\hline WS3 & (2) & (6) & $(0)$ & (0) & $(0)$ & (0) & $(0)$ & $(0)$ & $(0)$ & $(0)$ & $(0)$ & $(0)$ & $(2)$ & (1) & $(2)$ & (1) \\
\hline Unclassified bacteria & 13 & 46 & 8 & 3 & 3 & 2 & 0 & 4 & 4 & 4 & 0 & 3 & 5 & 2 & 4 & 4 \\
\hline Total & 294 & 1,101 & 82 & 80 & 74 & 74 & 80 & 78 & 80 & 75 & 80 & 84 & 78 & 75 & 76 & 85 \\
\hline
\end{tabular}

Numbers from respective "candidate division" phylotypes are in parentheses

Moss pillar microflora based on 16S rRNA gene analysis

The bacterial 16S rRNA gene was detected by PCR amplification in all samples from both moss pillars. No Archaeal $16 \mathrm{~S}$ rRNA was detected by PCR in any of the samples, despite several PCR runs. Therefore, only PCR products of bacterial 16S rRNA gene were cloned.

A total of 1,344 clones were obtained from specimen A for analysis, of which 1,101 could be used for phylotyping after excluding unclear sequence waveforms and chimera sequences. Phylotyping (>97\%) of these 1,101 clones yielded 294 phylotypes. Phylogenetic classification placed the 294 phylotypes in 16 clusters: 9 Cyanobacteria, 59 Alphaproteobacteria, 16 Betaproteobacteria, 5 Gammaproteobacteria, 30 Deltaproteobacteria, 1 unclassified Proteobacteria, 23 Bacteroidetes, 2 Nitrospirae, 12 Firmicutes, 41 Chloroflexi, 12 Actinobacteria, 36 Planctomycetes, 19 Acidobacteria, 10 Verrucomicrobia, 6 candidate divisions (1 OP11, 1 OD1, 2 TM7, 2 WS3), and 13 unclassified bacteria (Table 1; Table S2).

Overall, most nucleotide sequences were of Proteobacteria or close relatives. Cyanobacterial sequences were detected exclusively in the exterior, and obligate, anaerobic, gram-positive Clostridia (Firmicutes) were detected exclusively in the interior. This implies that some phylogenetic groups had pillar-wide distribution, while others were section-specific. The lowest exterior region of the moss pillar also contained 6 phylotypes (30\% of all analyzed clones) that were unclassifiable to any known groups of bacteria (candidate division OP11, OD1, TM7, WS3, unclassified bacteria). Rarefaction analysis shows no plateaus for the increasing numbers of phylotypes from exterior or interior sections of specimen A (Fig. 5) and specimen B (Fig. S1). More phylotypes would be generated from a greater number of PCR clones and further sequencing analyses, but greater "effort-per-catch" would also be needed.

\section{Dominant Proteobacteria in moss pillars}

Proteobacteria accounted for $111 / 294$ phylotypes (551/ 1,101 clones; $50 \%$ ) and dominated all 14 sections of the moss pillar interior and exterior (Table 1). Of these 111 phylotypes, 59/294 were Alphaproteobacteria (347/1,101 

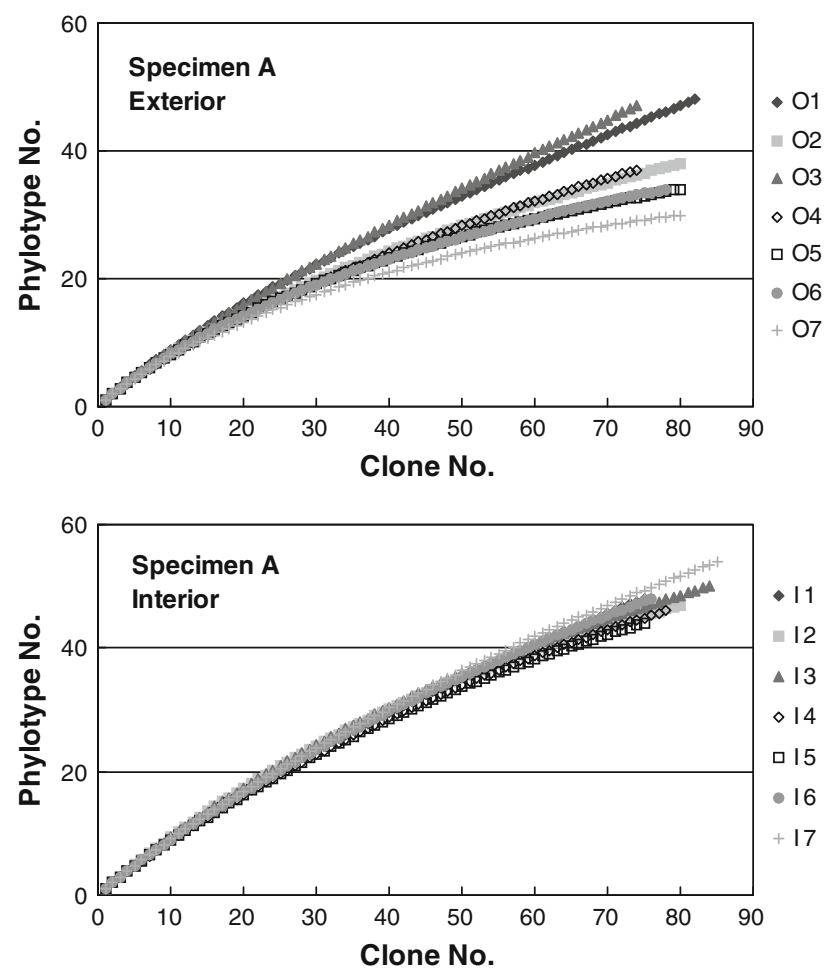

Fig. 5 Rarefaction curves for phylotypes and PCR clones of the 16S rRNA gene

clones; $31.5 \%)$. Clones of MPB1-33 (157/347 clones) were obtained from all 14 sections of the moss pillar. This phylotype was 99.4\% homologous with clone AS13 (EU283353) obtained from activated sludge and was also $89.4 \%$ homologous with the unclassified Alphaproteobacterium A0839. Another phylotype cloned from all 14 sections of the moss pillar was MPB1-27 (24/347 clones), which was $96.6 \%$ homologous with clone 655092 (AF236002) obtained from heavy metal-contaminated soil. This phylotype was also 92.1\% homologous with Bradyrhizobium, a genus of nitrogen-fixing bacterium, suggesting that such bacteria are responsible for nitrogen fixation throughout the whole moss pillar.

Betaproteobacteria accounted for 16/294 phylotypes (74/ 1,101 clones; $6.7 \%$ ). The most dominant phylotypes is MPB1-81 (34/74 clones), which was obtained from all sections of the pillar. This phylotype had a homology of $92 \%$ with the genus Thiobacillus. Moreover, some phylotypes were related to the known denitrifiers of the genera Denitratisoma and Sterolibacterium, and the homology range for each was $90.3-92.5$ and $91.5 \%$, respectively. In general, denitrification occurs under microaerobic conditions. Therefore, occurrence of these bacteria may contribute to denitrification near the oxic/anoxic interface in the pillar.

Deltaproteobacteria accounted for 30/294 phylotypes $(112 / 1,101$ clones; $10.2 \%)$. The most common among these 30 phylotypes was MPB1-104 (42/112 clones), which was
96\% homologous with clone HAVOmat82 (EF032751) obtained from caves in Hawaii Volcanoes National Park. This phylotype was also $85.9 \%$ homologous with sequences from species within the genus Geobacter. We also obtained phylotypes closely related to previously isolated sulfate-reducing bacteria-Desulfatirhabdium, Desulfonema-and sulfate-reducing bacterium STP23, with homologies of 94.9, 92.4, and 97\%, respectively. Since sulfate reduction is typical of microbial metabolism in anaerobic environments, this implies that sulfate reduction could occur in moss pillars, presumably in the anaerobic interior.

Cyanobacteria exclusive to the moss pillar exterior

Cyanobacteria are the main primary producers in Antarctic lakes (Vincent 1988, 2000; Quesada et al. 2008). Cyanobacteria accounted for $9 / 24$ phylotypes in our study (65/ 1,101 clones; $5.9 \%$ ), and all clones were obtained from the aerobic environment of the moss pillar exterior (Table 1). These phylotypes were closely related to the genera Leptolyngbya, Phormidium, Nostoc, and Synechococcus, with homologies ranging from 94.2 to $99.8 \%$. The most common phylotype was MPB1-3 (30/65 clones), which was cloned from all seven exterior sections. MPB1-3 had a perfect match (100\% homology) with clone RJ088 (DQ181681) obtained from benthic microbial mats in Reid Lake in the Larsemann Hills area of East Antarctica (Taton et al. 2006a). This phylotype was also $98.3 \%$ homologous with another Antarctic cyanobacteria, Leptolyngbya frigida ANT.LH64B.1 (AY493577) (Taton et al. 2006b). This finding is also in agreement with a previous report by Ohtani etal. (2001) who observed Leptolyngbya sp. through microscopy.

Firmicutes exclusive to the moss pillar interior

Firmicutes accounted for 12 of 294 phylotypes (47/1,101 clones; $4.3 \%$; Table 1), and phylotypes related to the sporeforming obligate anaerobes Clostridia were predominant. Interestingly, these phylotypes were obtained from the pillar interior; these data are consistent with the presence of gram-positive bacteria in the interior inferred from our fatty acid analysis. This strongly suggests that the moss pillar interior is an anaerobic environment that allows respiration by the Clostridia. The most common of the 11 Clostridia phylotypes was MPB1-149 (15/45 clones), which was 96.5\% homologous with a Clostridium estertheticum subsp. laramiense isolate. The second most common phylotype, MPB1-154 (11/45 clones), was 98.4\% homologous with a Clostridium bowmanii isolate. A phylotype obtained from the lowest part of the pillar interior (I1) was $96.7 \%$ homologous with a sulfate-reducing Desulfosporosinus isolate. Deltaproteobacteria and some types of Firmicutes may 
reduce sulfate (Kaneko et al. 2007), and thus such bacteria may well be responsible for sulfate reduction in the moss pillar interior.

Candidate divisions and unclassified bacteria detected in the lowest exterior of moss pillars

A candidate division is a putative division based on genetic clones isolated from the environment that do not belong to any known lineage. The 294 phylotypes obtained from the moss pillars included 19 phylotypes (80/1,101 clones; $7.3 \%$ ) unclassifiable in existing bacterial groups (Table 1). Of these, about $30 \%$ related to candidate divisions (OP11, OD1, TM7) and unclassified bacteria obtained from the lowest exterior section (O1). An example is the candidate division OP11, based on a 16S rRNA gene obtained from boiling mud springs at Yellowstone National Park (Hugenholtz et al. 1998). We obtained an OP11-related phylotype (7 clones) from the lowest part of the exterior section (O1). Another example is the candidate division OD1, which was described by Harris et al. (2004). We detected the phylotype (6 clones) related $(93.3 \%)$ to this division from the same part $(\mathrm{O} 1)$.

Clones related to these candidate divisions have been obtained from various anaerobic environments including freshwater and saltwater sediments (Wise et al. 1997; Li et al. 1999), hot mud springs (Hugenholtz et al. 1998), subsurface water (Watanabe et al. 2002; Miyoshi et al. 2005), soil (Kuske et al. 1997), and the human mouth (Paster et al. 2001). Although we obtained these candidate division clones from the presumably aerobic exterior $(\mathrm{O} 1)$, there is a possibility that this may have been because the lowest exterior section was contaminated by underlying semi-anaerobic or anaerobic sediments when the specimens were harvested. This could be clarified by analyzing the microflora in the sediment beneath the moss pillar specimens and comparing with the pillar microflora.

Reproducibility of 16S rRNA gene analysis of the second moss pillar

Of 1,344 clones obtained, 235 were excluded because of unclear sequence waveforms and chimera sequences, thus leaving 1,109 clones (Table 2). These yielded 270 phylotypes, of which 103 phylotypes (based on the $97 \%$ criterion) were found to be shared with specimen A phylotypes. These shared phylotypes represented $35 \%$ of specimen A phylotypes and $38 \%$ of specimen B phylotypes. Although this may not necessarily demonstrate the reproducibility of our microfloral analysis, it does show that some bacteria were common to both pillars. When the criterion for phylotype was lowered from $\geq 97 \%$ homology in the 16S rRNA gene (species-level similarity) to $90 \%$ (family-level similarity),
Table 2 Compared numbers of phylogenetically affiliated PCR clones of 16S rRNA gene sequences from the exterior and interior sections of moss pillar specimens A and B

\begin{tabular}{|c|c|c|c|c|}
\hline \multirow[t]{2}{*}{ Phylogenetic group } & \multicolumn{2}{|c|}{ Specimen A } & \multicolumn{2}{|c|}{ Specimen B } \\
\hline & Exterior & Inner & Exterior & Inner \\
\hline Cyanobacteria & 65 & 0 & 169 & 0 \\
\hline Alphaproteobacteria & 184 & 163 & 117 & 167 \\
\hline Betaproteobacteria & 31 & 43 & 8 & 52 \\
\hline Gammaproteobacteria & 5 & 7 & 9 & 5 \\
\hline Deltaproteobacteria & 62 & 50 & 9 & 80 \\
\hline $\begin{array}{l}\text { Unclassified } \\
\text { proteobacteria }\end{array}$ & 4 & 2 & 6 & 7 \\
\hline Bacteroidetes & 17 & 45 & 36 & 26 \\
\hline Nitrospirae & 1 & 11 & 0 & 4 \\
\hline Firmicutes & 0 & 47 & 0 & 45 \\
\hline Chloroflexi & 51 & 47 & 97 & 53 \\
\hline Actinobacteria & 5 & 20 & 22 & 3 \\
\hline Planctomycetes & 46 & 53 & 40 & 58 \\
\hline Acidobacteria & 15 & 23 & 2 & 11 \\
\hline Verrucomicrobia & 17 & 7 & 7 & 7 \\
\hline Caldiserica & 0 & 0 & 0 & 1 \\
\hline Gemmatimonadetes & 0 & 0 & 3 & 0 \\
\hline Candidate division & 21 & 13 & 13 & 9 \\
\hline OP10 & (0) & $(0)$ & (5) & (4) \\
\hline TM7 & (5) & (5) & $(0)$ & (3) \\
\hline WS3 & $(0)$ & (6) & $(0)$ & (0) \\
\hline OP11 & (8) & (2) & (7) & (2) \\
\hline OD1 & (8) & $(0)$ & (1) & (0) \\
\hline Unclassified bacteria & 24 & 22 & 26 & 17 \\
\hline Subtotal & 548 & 553 & 564 & 545 \\
\hline Total & 1,101 & & 1,109 & \\
\hline
\end{tabular}

Numbers from respective "candidate division" phylotypes are in parentheses

the number of phylotypes decreased and the number of phylotypes shared by both specimens increased to half or more of all phylotypes (data not shown). Rarefaction curves from both specimens (Figs 5 and S1) suggest generally high potentials for biodiversity. A tendency of no saturation, as shown by the absence of plateaus, is shared among all the samples, despite minor variation in the rarefaction profiles. Both specimens were dominated by Proteobacteria; Cyanobacteria were found exclusively in the exterior sections and Firmicutes exclusively in the interior (Tables 2, S2, S3).

However, the abundance of Cyanobacteria in the exterior differed between specimens, as reflected in clone occupancies of 5.9 and $15.2 \%$ of total clones in specimens A and $\mathrm{B}$, respectively. The specimens also differed in regard to candidate divisions and unclassified bacteria in the lowest exterior section, with abundance rates of $17.5 \%$ in 

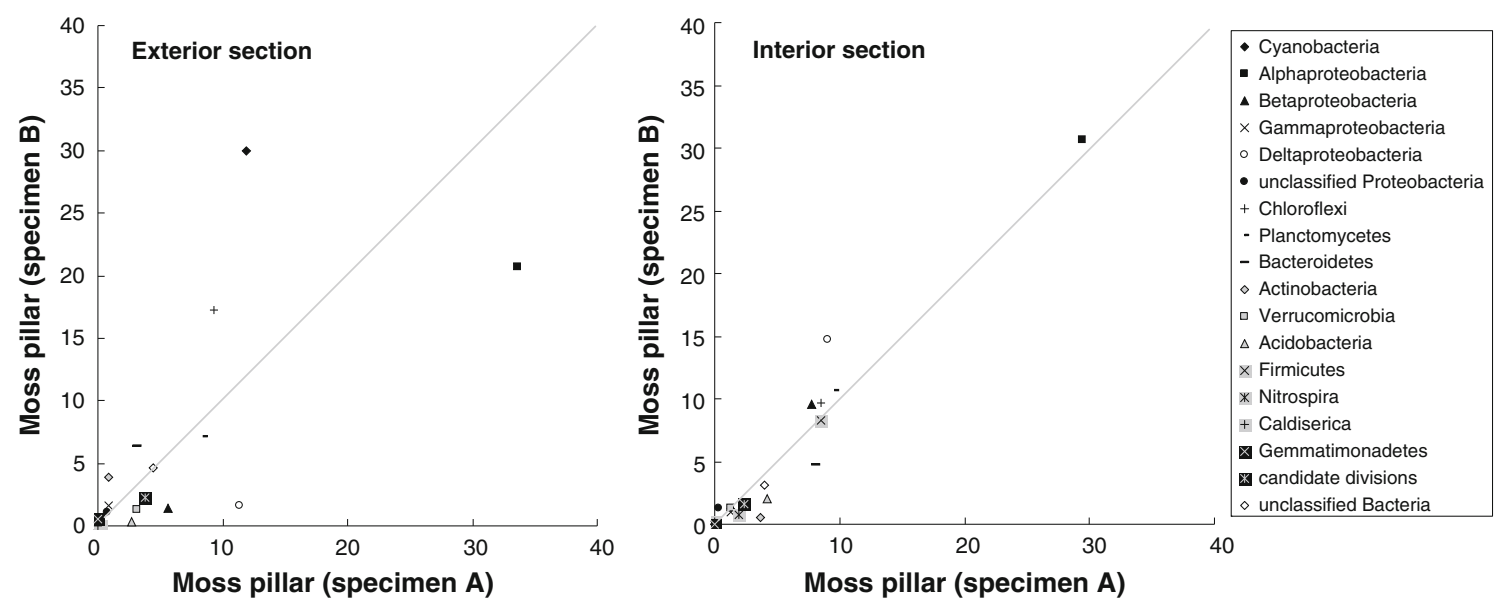

Fig. 6 Comparison of phylotype frequencies (\% of total) between moss pillar specimens A and B. Left exterior sections. Right interior sections

specimen B and 30\% in specimen A. These features also correspond with phylotype frequencies of specimens $\mathrm{A}$ and B. In particular, phylotype abundance of the interior of specimens A and B was more closely matched than that of the exteriors (Fig. 6). In other words, it is highly probable that interior microbial communities, less affected by environmental factors, are consistent across all moss pillars. Furthermore, since the moss pillar exterior is in direct contact with water, it is highly probable that microorganisms in the exterior may include phylotypes present in the water; this is likely to be reflected in the phylogenetic groups of our analysis.

\section{Conclusion}

The results of fatty acid and molecular phylogenetic analyses show that the whole moss pillar is dominated by Proteobacteria: the exterior is characterized by Cyanobacteria, the upper interior by gram-positive and sulfate-reducing bacteria, and the lower interior by gram-negative bacteria. In addition, nitrogen-fixing bacteria and denitrifying bacteria were detected by $16 \mathrm{~S}$ rRNA gene analyses. We hypothesize that these bacteria are all involved in the nitrogen cycle. This cycle within a benthic moss pillar appears to occur as follows: Nitrogen gas $\rightarrow$ (nitrogen fixation) $\rightarrow$ organic nitrogen $\rightarrow$ (decay) $\rightarrow$ ammonia $\rightarrow$ (nitrification) $\rightarrow$ nitrate $\rightarrow$ (denitrification) $\rightarrow$ nitrogen gas. It is possible that these bacteria are a valuable source of nitrogen for the existence and maintenance of these ecosystems in oligotrophic Antarctic lakes.

Our findings also suggest that microorganisms of different phylogenetic groups perform nitrogen fixation, denitrification, and sulfate reduction, and that these organisms inhabit different sections of a single moss pillar. Furthermore, this community may play a role in establishing and maintaining the structure by contributing different biochemical processes in oxidation-reduction equilibrium between the aerobic outer layer and the anaerobic inner layer. We propose to test these hypotheses by mapping the distribution of genes that encode functional enzymes involved in biogeochemical cycling processes.

Acknowledgments We gratefully acknowledge the members of the 42nd Japanese Antarctic Research Expedition (JARE). We thank Kazuko Ohishi and Tadasu Shin-i for their excellent technical help. This study was supported by the National Polar Research Institute and the Transdisciplinary Research Integration Center, Research Organization of Information and Systems, Japan. The study was conducted as part of Microbiological and Ecological Responses to Global Environmental Changes in Polar Regions (MERGE) during the International Polar Year of 2007-2008.

Open Access This article is distributed under the terms of the Creative Commons Attribution Noncommercial License which permits any noncommercial use, distribution, and reproduction in any medium, provided the original author(s) and source are credited.

\section{References}

Altschul SF, Madden TL, Schaffer AA, Zhang J, Zhang Z, Miller W, Lipman DJ (1997) Gapped BLAST and PSI-BLAST: a new generation of protein database search programs. Nucleic Acids Res 25:3389-3402

Ashelford KE, Chuzhanova NA, Fry JC, Jones AJ, Weightman AJ (2005) At least 1 in 20 16S rRNA sequence records currently held in public repositories is estimated to contain substantial anomalies. Appl Environ Microbiol 71:7724-7736

Beyer L, Bölter M (2002) Geoecology of Antarctic ice-free coastal landscapes. Springer, Berlin, pp 51-68

Christie WW (1982) Lipid analysis, isolation, separation, identification and structural analysis of lipids. Pergamon Press, Oxford

DeLong EF (1992) Archaea in coastal marine environment. Proc Natl Acad Sci USA 89:5685-5689

Findlay RH, Trexler MB, Guckert JB, White DC (1990) Laboratory study of disturbance in marine-sediments-response of a microbial community. Mar Ecol Prog Ser 62:121-133 
Gibson JAE, Wilmotte A, Taton A, van de Vijver B, Beyens L, Dartnall HJG (2006) Biogeography of Antarctic lakes. In: Bergstrom DM, Convey P, Huiskes AHL (eds) Trends in Antarctic terrestrial and limnetic ecosystems: Antartica as a global indicator. Springer, Dordrecht, pp 71-98

Harris JK, Kelley ST, Pace NR (2004) New perspective on uncultured bacterial phylogenetic division OP11. Appl Environ Microbiol 70:845-849

Hugenholtz P, Pitulla C, Hershberger KL, Pace NR (1998) Novel division level bacterial diversity in a Yellowstone hot spring. J Bacteriol 180:366-376

Imura S (2006) Ecosystem and geohistory of Antarctic lakes. Abstracts for XIII International Symposium on Polar Sciences, Incheon, Korea, pp 108-111

Imura S, Kanda H (2002) Aquatic moss vegetation at the bottom of Antarctic lakes. Bryol Res 8:69-73 (in Japanese)

Imura S, Bando T, Saito S, Seto K, Kanda H (1999) Benthic moss pillars in Antarctic lakes. Polar Biol 22:137-140

Imura S, Takahashi H, Nakamura T (2000) Benthic moss pillars (Koke Bouzu) in Antarctic lakes-analysis of colonization and growth by ${ }^{14} \mathrm{C}$ dating. Sum Res Using AMS Nagoya Univ XI:176-183 (in Japanese with English Abstract)

Imura S, Bando S, Seto K, Ohtani S, Kudoh S, Kanda H (2003) Distribution of aquatic mosses in the Syowa Coast region, East Antarctica. Polar Biosci 16:1-10

Iwasa T, Bando T, Nakamura T, Imura S (2000) The environmental changes presumed by AMS ${ }^{14} \mathrm{C}$ ages of algal sediments in Antarctic lakes, near the Syowa Station. Sum Res Using AMS Nagoya Univ XI:74-80 (in Japanese with English Abstract)

Kanda H (2009) The environmental and genetic approach for life on earth (EAGLE) project. Polar Sci 3:189-196

Kanekiyo A, Takasugi H, Ogawa M, Naganuma T (2005) Sediment fatty acids associated with seafloor methane seepage in the Nankai and Sagami Troughs, off central Japan. Aqua Ecosys Health Manage 8:73-80

Kaneko R, Hayashi T, Tanahashi M, Naganuma T (2007) Phylogenetic diversity and distribution of dissimilatory sulfite reductase genes from deep-sea sediment cores. Mar Biotech 9:429-436

Kimura S, Ban S, Imura S, Kudoh S, Matsuzaki M (2010) Limnological characteristics of vertical structure in the lakes of Syowa oasis, East Antarctica. Polar Sci 3:262-271

Kudoh S, Tuchiya Y, Ayukawa E, Imura S, Kanda H (2003a) Ecological studies of aquatic moss pillars in Antarctic lakes. 1: macro structure and carbon, nitrogen and chlorophyll $a$ contents. Polar Biosci 16:11-22

Kudoh S, Watanabe K, Imura S (2003b) Ecological studies of aquatic moss pillars in Antarctic lakes. 2: temperature and light environment at the moss habitat. Polar Biosci 16:23-32

Kudoh S, Kashino Y, Imura S (2003c) Ecological studies of aquatic moss pillars in Antarctic lakes. 3: light response and chilling and heat sensitivity of photosynthesis. Polar Biosci 16:33-42

Kudoh S, Tanabe Y, Matsuzaki M, Imura S (2009) In situ photochemical activity of the phytobenthic communities in two Antarctic lakes. Polar Biol 32:1617-1627

Kuske CR, Barns SM, Busch JD (1997) Diverse uncultivated bacterial groups from soils of the arid southwestern United States that are present in many geographic regions. Appl Environ Microbiol 63:3614-3621

Li W, Godzik A (2006) Cd-hit: a fast program for clustering and comparing large sets of protein or nucleotide sequences. Bioinformatics 22:1658-1659

Li L, Kato C, Horikoshi K (1999) Bacterial diversity in deep-sea sediments from different depths. Biodivers Conserv 8:659-677
Maidak BL, Cole JR, Lilburn TG, Parker CT Jr, Saxman PR, Farris RJ, Garrity GM, Olsen GJ, Schmidt TM, Tiedje JM (2001) The RDPII (ribosomal database project). Nucleic Acids Res 29:173-174

Matsumoto GI, Komori K, Enomoto A, Imura S, Takemura T, Ohyama Y, Kanda H (2006) Environmental changes in Syowa Station area of Antarctica during the last 2, 300 years inferred from organic components in lake sediment cores. Polar Biosci 19:51-62

Miller DN, Bryant JE, Madsen EL, Ghiorse WC (1999) Evaluation and optimization of DNA extraction and purification procedures for soil and sediment samples. Appl Environ Microbiol 65:47154724

Miyoshi T, Iwatsuki T, Naganuma T (2005) Phylogenetic characterization of 16S rRNA gene clones from deep-groundwater microorganisms that pass through 0.2-micrometer-pore-size filters. Appl Environ Microbiol 71:1084-1088

Naganuma T, Miyoshi T, Kimura H (2007) Phylotype diversity of deep-sea hydrothermal vent prokaryotes trapped by 0.2 - and 0.1- $\mu \mathrm{m}$-pore-size filters. Extremophiles 11:637-646

Ohtani S, Kudoh S, Tsuchiya Y, Suyama K, Imura S (2001) Species composition of freshwater algae in benthic moss pillars in lakes, Skarvsnes, Antarctica. Abstracts for XXIV Symposium on Polar Biology Tokyo, Natl Inst Polar Res 77

Ohtsuka T, Kudoh S, Imura S, Ohtani S (2006) Diatoms composing benthic microbial mats in freshwater lakes of Skarvsnes ice-free area, East Antarctica. Polar Biosci 20:113-130

Paster BJ, Boches SK, Galvin JL, Ericson RE, Lau CN, Levanos VA, Sahasrabudhe A, Dewhirst FE (2001) Bacterial diversity in human subgingival plaque. J Bacteriol 183:3770-3783

Quesada A, Fernandez-Valiente E, Hawes I, Howard-Williams C (2008) Benthic primary production in polar lakes and rivers. In: Vincent WF, Laybourn-Parry J (eds) Polar lakes and rivers. Oxford University Press, Oxford, pp 179-196

Rajendran N, Matsuda O, Imamura N, Urushigawa Y (1992) Variation in microbial biomass and community structure in sediments of eutrophic bays as determined by phospholipid ester-linked fatty acids. Appl Environ Microbiol 58:562-571

Tanabe Y, Kudoh S, Imura S, Fukuchi M (2008) Phytoplankton blooms under dim and cold conditions in freshwater lakes of East Antarctica. Polar Biol 31:199-208

Taton A, Grubisic S, Balthasart P, Hodgson DA, Laybourn-Parry J, Wilmotte A (2006a) Biogeographical distribution and ecological ranges of benthic cyanobacteria in East Antarctic lakes. FEMS Microbiol Ecol 57:272-289

Taton A, Grubisic S, Ertz D, Hodgson DA, Piccardi R, Biondi N, Tredici M, Mainini M, Losi D, Marinelli F, Wilmotte A (2006b) Polyphasic study of Antarctic cyanobacterial strains. J Phycol 42:1257-1270

Vincent WF (1988) Microbial ecosystems of Antarctica. Cambridge University Press, Cambridge

Vincent WF (2000) Cyanobacterial dominance in the polar regions. In: Whitton BA, Potts M (eds) The ecology of cyanobacteria: their diversity in time and space. Kluwer Academic Press, Dordrecht, pp 321-340

Wang Q, Garrity GM, Tiedje JM, Cole JR (2007) Naive Bayesian classifier for rapid assignment of rRNA sequences into the new bacterial taxonomy. Appl Environ Microbiol 73:5261-5267

Watanabe K, Kodama Y, Hamamura N, Kaku N (2002) Diversity, abundance, and activity of archaeal populations in oil-contaminated groundwater accumulated at the bottom of an underground crude oil storage cavity. Appl Environ Microbiol 68:3899-3907

Wise MG, McArthur JV, Shimkets LJ (1997) Bacterial diversity of a Carolina bay as determined by $16 \mathrm{~S}$ rRNA gene analysis: confirmation of novel taxa. Appl Environ Microbiol 63:1505-1514 